A Review of Evidence: Using Respirators to prevent Sars-Cov-2 Transmission

\author{
Author Contact Information \\ Adam Nulty \\ Higher Aushaw Farm \\ Roman Road \\ Darwen \\ Lancashire \\ BB3 3PP \\ England \\ Institutional Affiliations \\ Phd Research Student \\ University of Leeds \\ Woodhouse Lane \\ Leeds \\ LS2 9JT \\ England
}




\title{
A Review of Evidence: Using Respirators to prevent Sars-Cov-2 Transmission
}

\begin{abstract}
A.Nulty
Abstract

This literature review has been compiled to form an evidenced-based review on the standards for Dental Practices in their choice and use of personal protective equipment (PPE) within the COVID-19 Pandemic and beyond: it is prepared on the basis of the current best available evidence. The review encompasses risk management strategies for both Dental Personnel and Patients in the application and use of Face Masks \& Respirators.

In summation, from the evidence available, it is apparent that in the lab setting N95/FFP2 masks are superior in their efficiency but in the clinical setting such a difference is not seen as clearly. As such the minimum standard of care should be that of a standard surgical mask. Faced with the emergence of the virulent disease that is Covid-19, it is logical to use FFP2/N95 respirator masks in aerosol generating procedures where they offer greater resistance to fluid penetration and a better face seal when adequately fit tested as a gold standard. But if a dry field isolation technique involving high volume evacuation is used, there is no clear benefit of respirator masks (N95/FFP2 or N99/FFP3) when balanced with the extra risk of compliance, cost and comfort in wearing a standard fluid-resistant surgical mask.
\end{abstract}




\section{$\underline{\text { In Brief }}$}

1) N95/FFP2 masks are superior in their efficiency but in the clinical setting such a difference is not seen as clearly

2) The minimum standard of care should be that of a standard surgical mask.

3) If a dry field isolation technique involving high volume evacuation is used, there is no clear benefit of N95/FFP2 or N99/FFP3 when balanced with the extra risk of compliance, cost and comfort in wearing a standard fluid-resistant surgical mask. 


\section{Introduction}

In epidemics of highly infectious diseases, such as Ebola, SARS and now the Sars-COV-2 Coronavirus pandemic, dental professionals and healthcare workers in the dental setting are reported to be probably at greater risk than the general population, due to their close contact with patients and their potentially contaminated bodily fluids. ${ }^{1}$

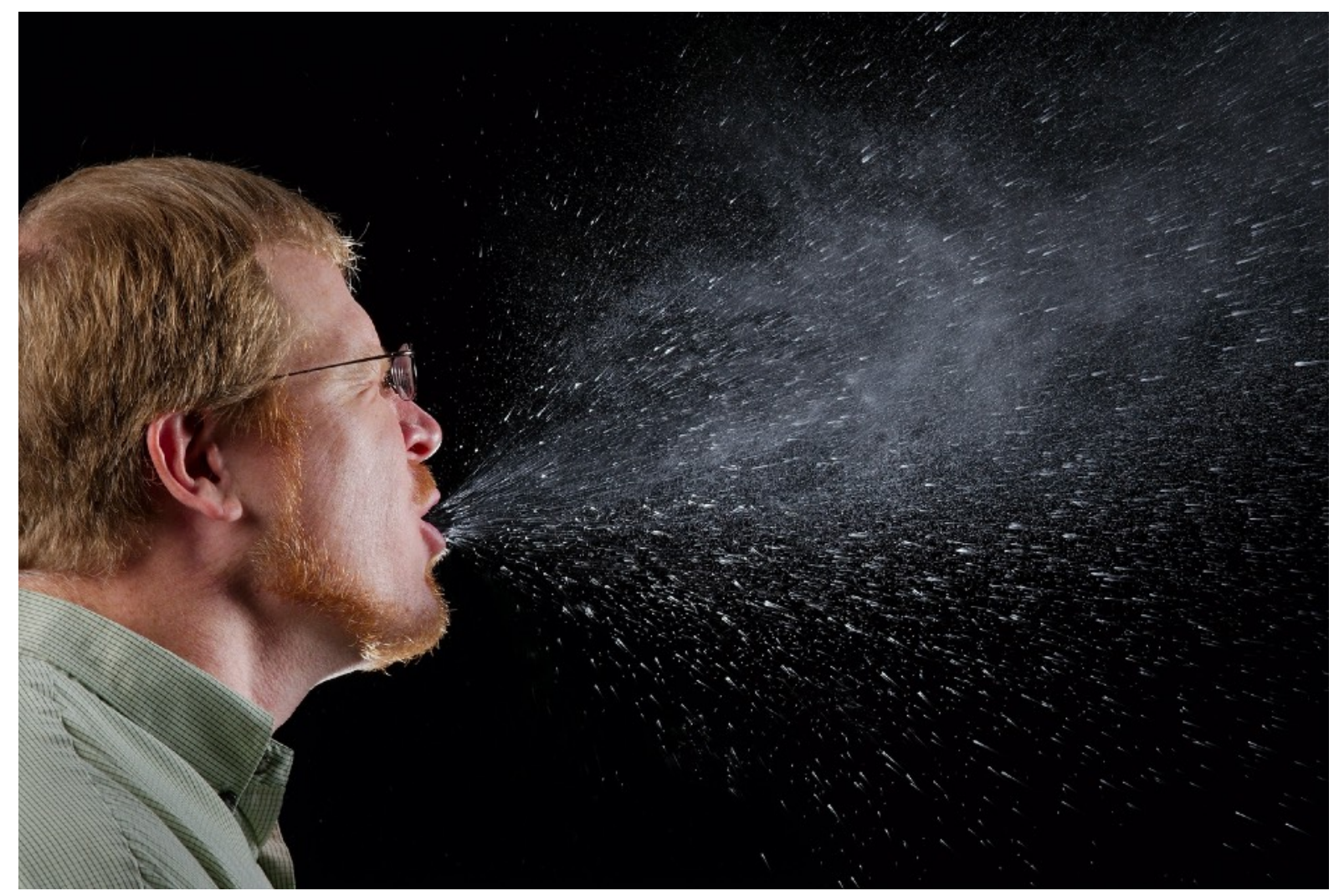

Figure 1. Respiratory droplets released through talking, coughing, or sneezing

The be effective and also practical, PPE such as masks and respirators must prevent respiration of the bacterial or viral particulate but should also be comfortable. The use of respirators requires compliance to be effective. ${ }^{2}$ When comfort is lacking, overprotection can introduce problems. For example, in proposing the use of masks of higher rating in some scenarios, these higher rated masks such as N99/FFP3 masks may make work more difficult and uncomfortable and eventually lead to an increased, rather than decreased, risk of infection as they increase the burden on the clinician or worker to perform. ${ }^{3}$ 
The Control of Substances Hazardous to Health Regulations 2002 (COSHH) in the United Kingdom, covers not only exposure to hazardous chemicals but also biological agents. The regulations assert that 'every employer shall ensure that the exposure of his employees to substances hazardous to health is either prevented or, where this is not reasonably practicable, adequately controlled ${ }^{4}$.' Where PPE is employed as a control measure then it should be 'adequate' for the anticipated exposure levels and 'suitable' for the task, for the environment and for the wearer. In addition the PPE must be:

1. "CE" marked to the European PPE Directive;

2. Selected, used and maintained by properly trained people;

3. Correctly maintained, examined and tested;

4. Correctly stored.

The British Standard BS EN 149:2001 covers disposable filtering facepiece (FFP) respirators. FFP respirators are classified according to the level of protection afforded as assessed by specified laboratory tests, with FFP3 offering the most protection. ${ }^{5}$

\begin{tabular}{|l|l|l|l|l|l|}
\hline Class & $\begin{array}{l}\text { Max permitted } \\
\text { total inward } \\
\text { leakage }\end{array}$ & $\begin{array}{l}\text { Max permitted } \\
\text { filter } \\
\text { penetration }\end{array}$ & $\begin{array}{l}\text { Min filter } \\
\text { efficiency }\end{array}$ & $\begin{array}{l}\text { Nominal Pro- } \\
\text { tection Factor } \\
+\dagger\end{array}$ & $\begin{array}{l}\text { Assigned } \\
\text { Protection } \\
\text { Factor }\end{array}$ \\
\hline FFP1 & $22 \%$ & 20 & $80 \%$ & 4.5 & 4 \\
\hline FFP2 & $8 \%$ & 6 & $94 \%$ & 12.5 & 10 \\
\hline FFP3 & $2 \%$ & 1 & $99 \%$ & 50 & 20 \\
\hline
\end{tabular}

Table 1. Efficiency requirement for filtering facepieces and their assigned protection factors 5 ( ${ }^{\dagger}$ Figure derived from the maximum filter penetration allowed by BS EN 149:2001)

$\left({ }^{\dagger \dagger}\right.$ Figure derived from the maximum total inward leakage allowed by BS EN 149:2001)

The European PPE Regulation Guidelines covers Respiratory Protective Equipment. This Directive excludes surgical masks and they are not certified for use as RPE in the UK. Surgical masks can be certified compliant with the Medical Devices Directive and be 'CE' marked. However, the placing of a 'CE' mark on a surgical mask does not denote the ability to provide respiratory protection under the PPE Directive. 6,7 Whilst surgical masks do provide a degree of protection against droplets and splashing, the British Standard covering surgical masks (BS EN 14683:2005)9 ${ }^{9}$ states that: 
'The surgical masks intended to be used in operating theatres and health care settings with similar requirements are designed to protect the working environment and not the wearer. When the primary intention is to protect the wearer from infection, the use of respiratory protective devices should be considered'.

Requirements by British-Adopted European Standard BS EN 149:2001 and NIOSHH standards are such that respirator masks have the following protection:

N95/FFP2 - Maximum permitted inward leakage - 8\%. Minimum Filter efficiency - 94\% N99/FFP3 - Maximum permitted inward leakage - 2\%. Minimum Filter efficiency - 99\%

Whilst it may seem sensible in the time of a pandemic to use the maximum filter efficiency type respirator mask, N99/FFP3 masks are inherently uncomfortable and can become intolerable in long periods of wear. ${ }^{8}$ Respirator masks require the use of a fit test to confirm efficiency and breathing ability. However, healthcare workers may find difficulty in achieving suitable generic sizing to sufficiently fit. Studies of respirator mask fit in workforces have shown large differences in how well the respirator mask fits. In one study only $36-62 \%$ of staff passed the fit test required to confirm effectiveness to N99/FFP3 standard due to variance in facial shape. ${ }^{9}$

Another common reason for breach of the PPE barrier is sweating and poor breathing ability causing the worker to wipe their face or adjust the PPE visor or mask. ${ }^{10}$

A Cochrane Systematic Review of Personal protective equipment for preventing highly infectious diseases due to exposure to contaminated body fluids in healthcare staff found very low quality evidence that more breathable types of PPE (eg. FFP2 vs FFP3) may not lead to more contamination, but may have greater user satisfaction. ${ }^{11}$

Another recent Cochrane review on the re-opening of dental services from 16 international sources discuss the most common approach to the types of Masks and respirators used. "Most sources recommend filtering facepiece class 2 (FFP2, equivalent to N95) masks for non-COVID-19 cases undergoing AGPs and all suspected or confirmed COVID-19 cases undergoing any procedure."12

It is therefore clear that dental professionals working in practice are to wear appropriate levels of PPE dependent on the type of care provided. 


\section{The Evidence Base for Face Mask Usage}

Face masks make up one component of barrier protective equipment, the others being eyewear, gloves, face shields and protective outerwear. The use of a standard fluid-resistant surgical mask (FRSM), or FFP2 (N95) mask or indeed FFP3 (N99) mask and their relative effectiveness has been widely debated. The current standard operating procedure from NHSE advises the use of FFP3 (N99) masks in all Urgent Dental Care Centres and this was understandable given the available information about Sars-COV-2 at the time.

Face masks were introduced to minimise post surgical infection in patients from exhaled microbes shed by the surgical team. ${ }^{13}$ As healthcare has evolved, so has the realisation that the face mask protects the healthcare worker in equal respect. The transmission of airborne infection depends on the virulence and particulate viral load respirated. ${ }^{14}$ In the case of SARS-Cov-2 coronavirus, the viral transmission is believed to be of the same route as that of coronavirus-induced pneumonia leading to SARS i.e. through airborne droplet transmission. ${ }^{15}$

Therefore for standard, non-aerosol generating procedures (non-AGPs), standard 3-ply surgical masks have been shown to be as effective as respirator masks. ${ }^{16}$ Furthermore, for non-AGPs, there is no evidence that respirator masks add value over standard masks when both are used with the recommended wider PPE and risk reducing measures as outlined in this guidance. ${ }^{17}$

In a recent meta-analysis of N95 respirators vs Surgical masks in the prevention of infection transmission of influenza, showed that whilst in the laboratory setting the N95 mask may have the benefit of smaller particle filtration, there is insufficient data to definitively determine superiority in clinical settings. ${ }^{18}$ However, N95 respirators have been associated with less filter penetration and face-seal leakage compared with surgical masks. ${ }^{19}$

Overall there is a paucity of data and studies comparing surgical masks and N95/FFP2 or N99/FFP3 respirator masks in mitigating the risk of transmission of the SARS-Cov-2 virus from the patient to the clinical team. However there is data that compares these masks in their protection against the influenza virus ${ }^{20}$ and SARS 21.

When the overall performance of surgical masks, N95 masks and N99 masks are compared in their performance against viral aerosols, studies have demonstrated that the protection factor of N95 was thirty times greater when compared to surgical masks. 22,23 
Liverman et al developed a report and made conclusions and recommendations on behalf of the Institute of Medicine (IOM) Committee on Respiratory Protection for Healthcare Workers in the Workplace against the Novel H1N1 Influenza A. In that report they describe a cluster randomized clinical trial that was conducted to compare the clinical efficacy of standard surgical masks versus N95/FFP2 masks with and without fit testing, versus control in influenza transmission in 1,936 healthcare workers in China. The N95/FFP2 masks were found to have statistically significant efficacy, while surgical masks showed no efficacy. Although overall conclusions were difficult to be drawn as the authors stated that they did not have the full details of the study. ${ }^{24}$

\section{Compliance and Face Mask Usage}

In comparing standard surgical masks with the efficiency of N95/FFP2 or N99/FFP3 masks, it is also important to reflect on user compliance. It is feasible that the improved efficiency of an N95/FFP2 or N99/FFP3 respirator over a standard surgical mask may be reduced if compliance is poor due to comfort in long clinical sessions.

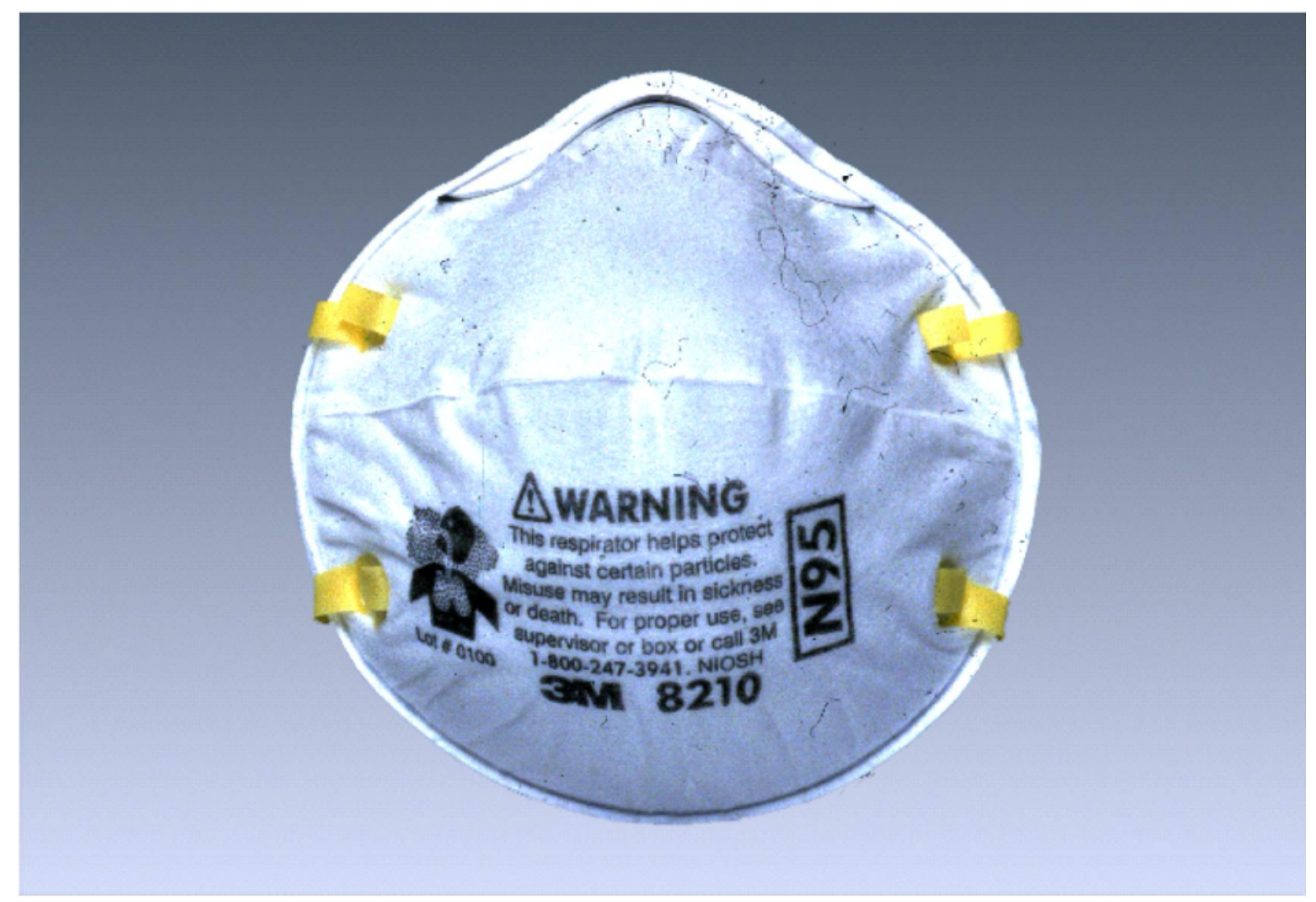

Figure 2. An example of an N95 respirator. 


\section{Required Labeling of NIOSH-Approved N95 Filtering Facepiece Respirators}

For more information about NIOSH-Approved respirators, go to: http://knowits.NIOSH.gov

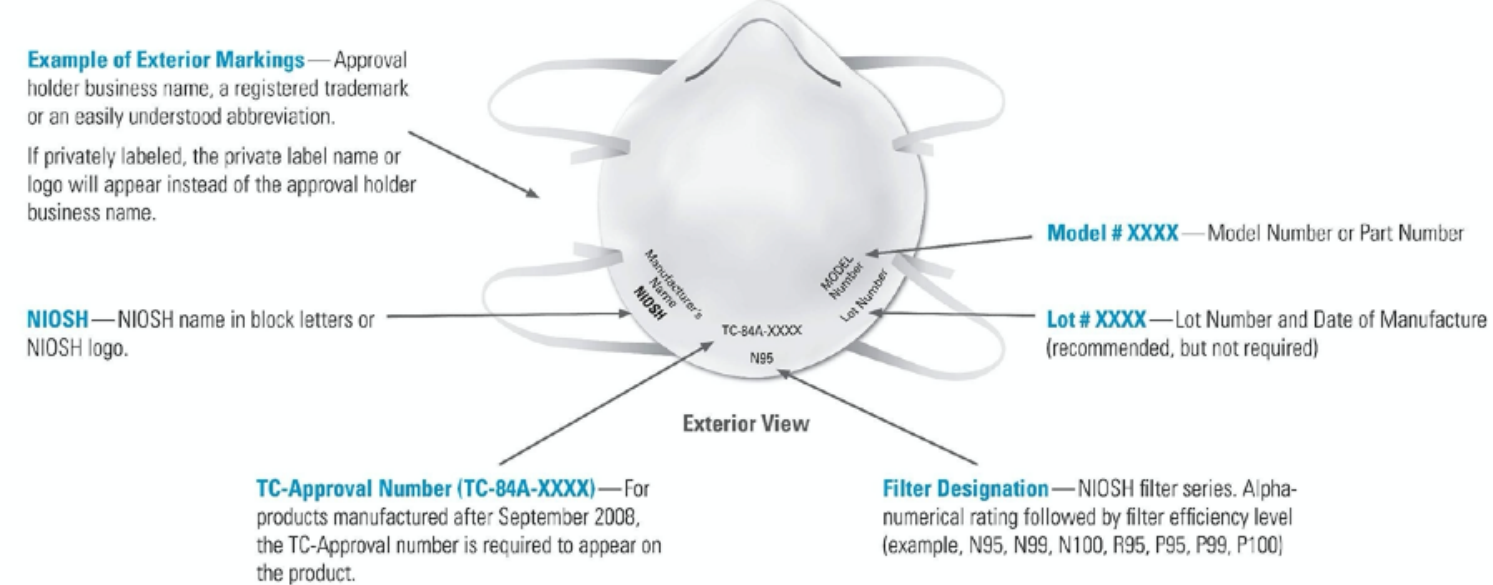

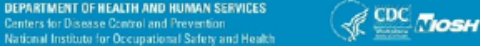

Figure 3. An infographic on respirator usage.

The very small gains offered by N99/FFP3 over N95/FFP2 are negated by the increased risks introduced through poor wearer comfort (touching mask to adjust, breathing difficulties, creation of fomites, skin damage and face sores) due to the tighter fitting respirator that is more difficult to breath through. ${ }^{25}$ The greater comfort of the N95/FFP2 respirator therefore makes it the mask of choice for dental AGPs.

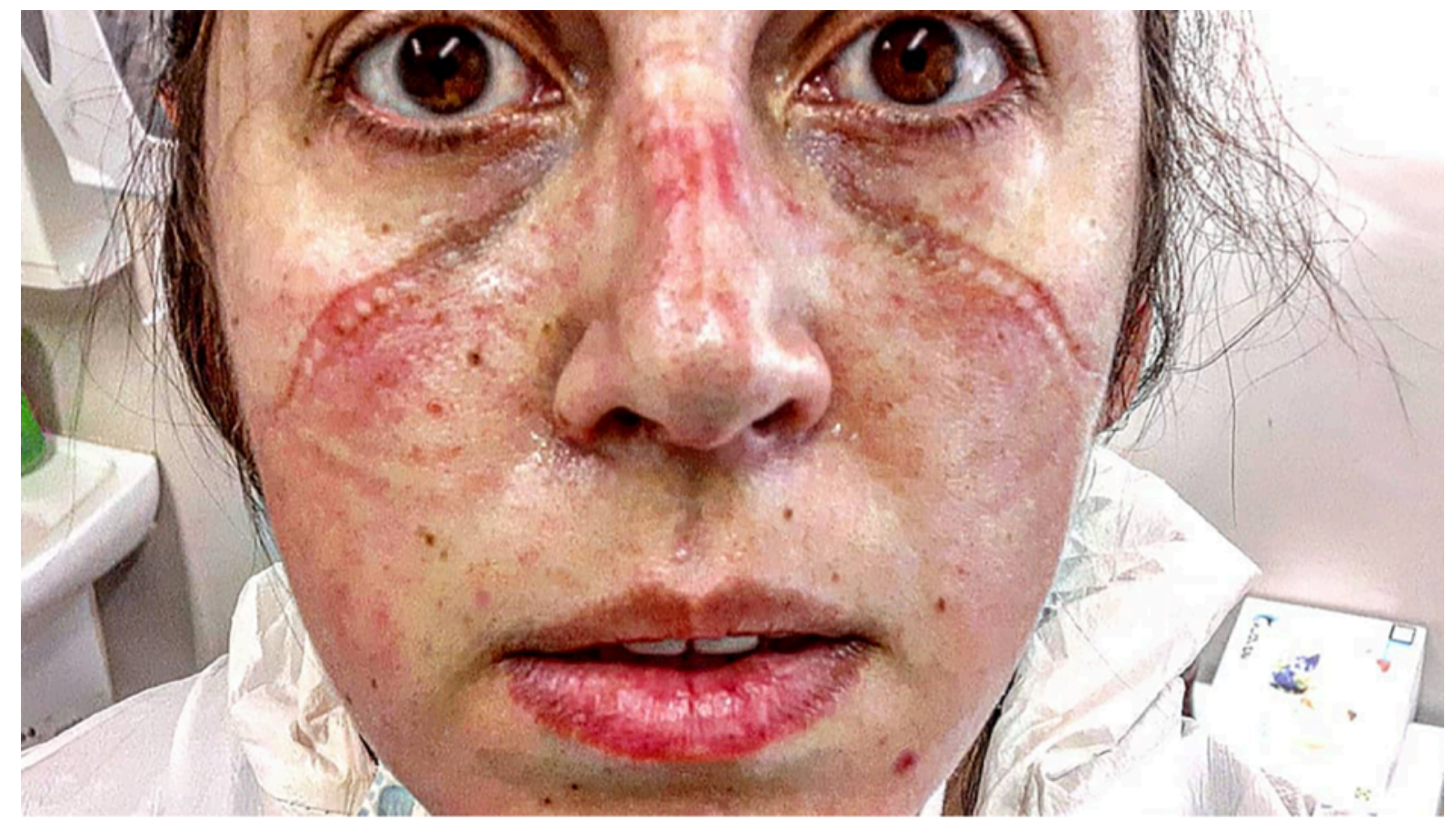

Figure 4. An example of skin fomites from the wearing of respirators for long periods. ${ }^{35}$ 
Some N95/FFP2 masks may be commercially available and certified as re-usable. However, it is important that these re-usable masks have a clear and medically certified method for sterilisation. The Sars-COV-2 virus has been shown to have the ability to remain active on the respiratory surface for upto three days on plastic ${ }^{26}$ and hence their repeated use can only be recommended when used in combination with a medically certified method of cleaning and sterilisation.

It is also clearly important to understand whether there is any increased risk of transmission from an aerosol generated procedure, if extra precautions such as high volume suction devices are employed ie whether there is any overall benefit to the use of N95/FFP2 respirator masks in these AGP procedures. If aerosols can be actively reduced, then the risk of transmission would therefore reduce in turn.

In a study by Yamada et al27 to understand the aerial dispersal of blood-containing aerosols in various dental procedures, the study was clear that without high volume suction there is a dissemination of the blood within the operating area but it can be concluded that the relevance of the findings with regards to respirator pathogens is likely to be insignificant.

However, a study by Rautemaa et al does provide evidence that procedures involving high-speed and ultrasonic dental instruments can cause significantly greater contamination than non-agp procedures and also provides weak evidence of these procedures generating small inhalable aerosols. ${ }^{28}$

There is a lack of studies on methods of reducing these aerosols - such as high volume suction - and their relation to transmission risk with respiratory pathogens. We need to consider this to enable a fair and evidence based assessment of the need to employ greater protection during AGP procedures. A paper from the MUSC research team in the United States has studied an evaluation of the Spatter-Reduction effectiveness and aerosol containment of 8 Dry-Field isolation techniques. This study is clear that spatter and aerosols are reduced in the region of $99.7 \%$ when high volume evacuation (HVE) devices. ${ }^{29}$ 


\section{Fit Testing}

N95/FFP2 masks come in a variety of shapes and sizes. Fit testing is required to determine if a particular size or model provides an acceptable fit for the individual. The benefits of N95/FFP2 respirator masks used in aerosol generating procedures will be negated if the mask does not form a tight seal around the face and nose and therefore fit testing is required.

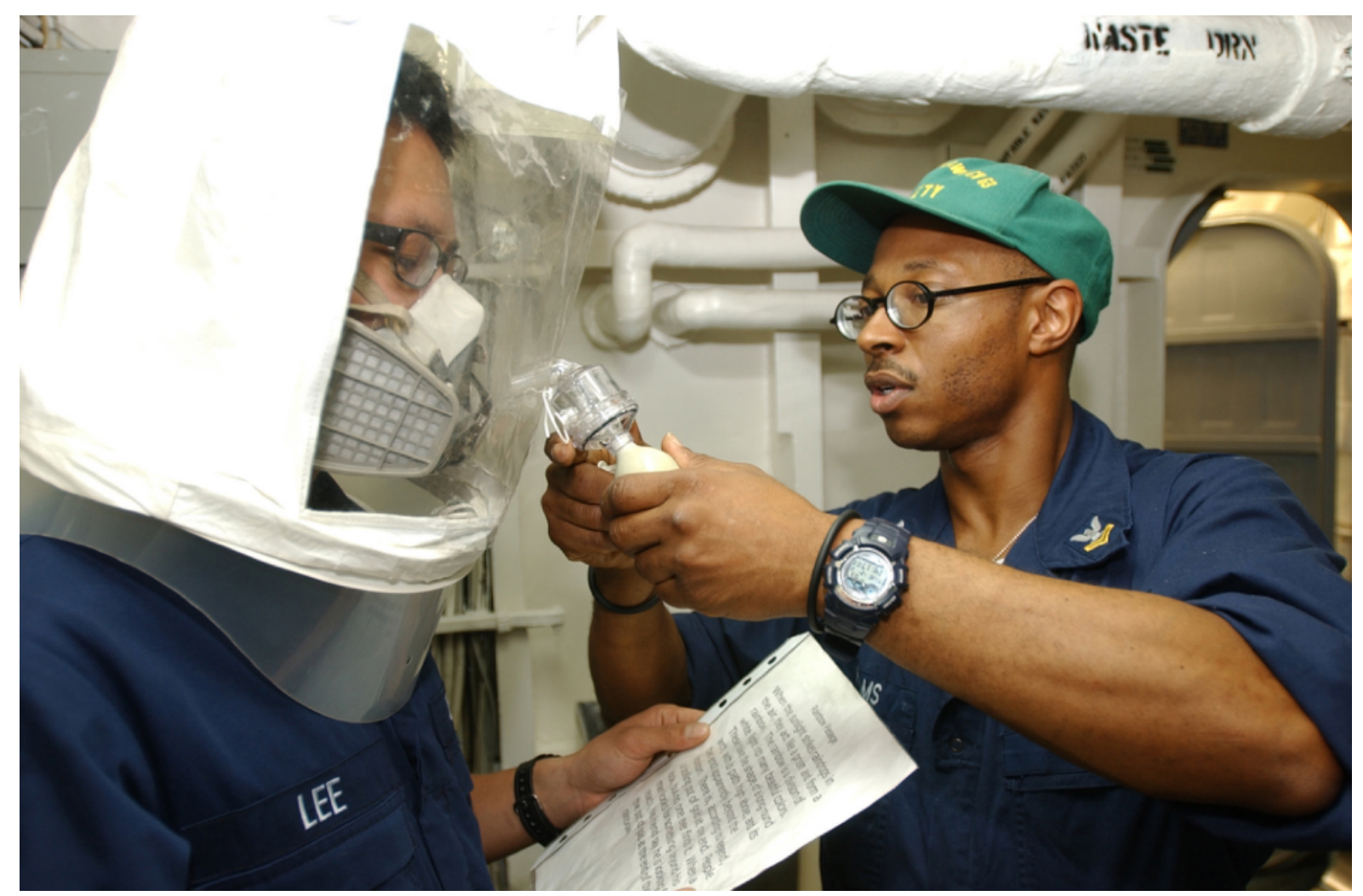

Figure 5. A Fit testing procedure being carried out to check respirator seal.

\section{Fit test}

A fit test is conducted by a trained fit tester to verify that the respirator device performs as intended and is both comfortable and effective. Fit tests are either qualitative or quantitative.

\section{- Qualitative}

A pass/fail test method using a hood over the head of the staff member. The test uses the staff member's sense of taste or smell to detect a test substance introduced into the surrounding air space. This can include;

o Isoamyl acetate - which smells like bananas

o Saccharin - which leaves a sweet taste in the mouth 
o Bitrex - which leaves a bitter taste in the mouth

o Irritant smoke - which causes coughing

Qualitative fit testing does not detect the amount of leakage, and the pass/fail result is solely dependent on the detection of the test substance.

- Quantitative

A qualitative test uses a machine to measure the actual leakage of the respirator mask. The mask type used requires a probe attachment to be fitted or pierced into the mask to allow connection to the machine through a hose.

\section{Self Seal-Test}

A user seal check should be conducted by the staff member using the N95/FFP2 face mask upon donning, to confirm positive and negative pressure seal.

- During positive pressure seal check, the staff member exhales gently whilst blocking the paths of air to escape and exit the facepiece. On slight pressurisation, there should be no leakage.

- During a negative pressure seal check, the staff member inhales sharply whilst again maintaining pressure blocking the paths of air escape

\section{Facial Hair}

In order to achieve the best levels of protection, we strongly advise that employees are clean shaven in the area of the seal before they begin their shift or take a face fit test. 30

\section{Overall Guidelines for Mask \& Respirator Usage}

In principle, surgical masks that are worn correctly should provide adequate protection against large droplets, splashes and contact transmission. They may also reduce to some degree any residual aerosol risk, although this level of protection might not sufficiently reduce the likelihood of transmission via this route. Consequently they should not be used in situations where close exposure to infectious aerosols is likely, ${ }^{31,32}$ when better fitting respirator type 2 (N95/FFP2) masks are available.

Importantly, masks and respirators should not be considered as isolated interventions. Other protection includes hand hygiene, aprons or gowns, goggles or face shields, and gloves. 
When considering the above literature and current evidence base, it can be concluded that a basic minimum standard of protection is surgical face masks. For procedures that require aerosol generating procedures should involve the use of N95 (FFP2) masks to further protect the respiratory tract if no HVE device is used. If a HVE device is used there should be no requirement to the use of N95(FFP2) or N99(FFP3) respiratory masks.

\section{Conclusion}

There are many challenges that a Dental Practice and individual Dental Practice staff members will need to overcome to minimise risk of transmission of the Sars-COV-2 virus.

The vast majority of Dental Practice owners will want to maintain treatment provision to that which was routinely provided before the escalation and lockdown that occurred with the COVID-19 pandemic. All Dental Professionals will be eager to serve their patients to the best of their ability, in patients' best interests, whilst using current evidence based guidance to create a Standard Operating Protocol for their clinic. Respiratory protection is one part of a systematic multi-pronged infection prevention and control strategy.

In summation, from the evidence available, it is apparent that in the lab setting N95/FFP2 masks are superior in their efficiency but in the clinical setting such a difference is not seen as clearly. As such the minimum standard of care should be that of a standard surgical mask. Faced with the emergence of the virulent disease that is Covid-19, it is logical to use FFP2/N95 respirator masks in aerosol generating procedures where they offer greater resistance to fluid penetration and a better face seal when adequately fit tested as a gold standard. But if a dry field isolation technique involving high volume evacuation is used, there is no clear benefit of N95/FFP2 or N99/FFP3 when balanced with the extra risk of compliance, cost and comfort in wearing a standard fluid-resistant surgical mask.

The author acknowledges that there are many issues and risk factors which a practice will undoubtedly examine in their decision making process to form clinical operating procedures. As the pandemic progresses and more clinical and research data becomes available worldwide, we may 
find that the universal precautions that we have always undertaken, which include surgical masks, face shields and high volume suction, will be sufficient and the clinicians choice of risk reduction through the use of surgical mask or respirator must then be reviewed accordingly.

Through the adoption of the protocols outlined in this literature review and other evidence based guidance issued in their respective country, these dental practices will be able to both minimise risk and also practice in a timely and efficient manner and above all, in the best interests of patients and staff. 


\section{Aknowledgements}

\section{Conflict of interest statement}

There is no conflict of interest to declare.

The author has no financial interests or connections, direct or indirect, that might compromise the perception of the authors as impartial. There is no financial interest that includes commercial or other sources of funding for the author or associated department(s) or organization(s), personal relationships, or direct academic competition.

\section{Author Contributions}

Author: Adam Nulty

Contributed to conception, design, data acquisition and interpretation, drafted and critically revised the manuscript

All authors gave their final approval and agree to be accountable for all aspects of the work. 


\section{$\underline{\text { References }}$}

1. Office for National Statistics. 2020. Which occupations have the highest potential exposure to the coronavirus (COVID-19)?

2. Nichol K, Bigelow P, O’Brien-Pallas L, McGeer A, Manno M,Holness DL. 2008. The individual, environmental, and organizational factors that influence nurses' use of facial protection to prevent occupational transmission of communicable respiratory illness in acute care hospitals. American Journal of Infection Control. 36(7):481-7.

3. Roberge RJ. 2008. Evaluation of the rationale for concurrent use of N95 filtering face piece respirators with loose-fitting powered air-purifying respirators during aerosol-generating medical procedures. American Journal of Infection Control. 36(2):135-41.

4. HSE. 2004. Control of substances hazardous to health regulations 2002 (as amended in 2004) - General enforcement guidance and advice. OC 273/20 v2

5. HSE. 2008. Evaluating the protection afforded by surgical masks against influenza bioaerosols.

6. EU. 2018. PPE Regulation Guidelines. 1st edition.

7. BSI. 2019. BS EN 14683:2005 Medical face masks. Requirements and test methods STANDARD by British-Adopted European Standard.

8. Locatelli SM, LaVela SL, Gosch M. 2014 Health care workers' reported discomfort while wearing filtering face-piece respirators. Workplace Health Saf. 62(9):362-368.

9. Foereland S, Robertsen O, Hegseth MN. 2019. Do Various Respirator Models Fit the Workers in the Norwegian Smelting Industry?. Saf Health Work. 10(3):370-376.

10. Cherrie JW, Semple S, Christopher Y, Saleem A, Hughson GW, Philips A. 2006. How important is inadvertent ingestion of hazardous substances at work?. Annals of Occupational Hygiene. 50(7):693-704.

11. Verbeek JH, Rajamaki B, ljaz S, Tikka C, Ruotsalainen JH, Edmond MB, Sauni R, Kilinc Balci FS. 2019. Personal protective equipment for preventing highly infectious diseases due to exposure to contaminated body fluids in healthcare staff. Cochrane Database of Systematic Reviews, Issue 7. Art. No.: CD011621.

12.COVID-19 Dental Services Evidence Review (CoDER) Working Group. 2020. Recommendations for the re-opening of dental services: a rapid review of international sources Version 1.3. [Accessed 16th May 2020]

13. Hogan B, Samaranayake LP. 1990. The surgical mask unmasked: a review. Oral Surg Oral Med Oral Pathol. 69:329-31.

14. Musher D. 2003. Medical progress: how contagious are common respiratory tract infections? N Engl J Med. 348:1256-66. 
15. Yu IT, Li Y, Wong TW. 2004. Evidence of airborne transmission of the severe acute respiratory syndrome virus. N Engl J Med. 350:1731-9.

16. Greenhalgh T. Chin XH. 2020. What is the efficacy of standard face masks compared to respirator masks in preventing COVID-type respiratory illnesses in primary care staff? [Accessed 16th May 2020] https://www.cebm.net/wp-content/uploads/2020/03/COVID-CAT-PPE-MASKS-9-REVISED-002.pdf

17. Long Y, Hu T, Liu L, et al. 2020. Effectiveness of N95 respirators versus surgical masks against influenza: A systematic review and meta-analysis [published online ahead of print, 2020 Mar 13]. J Evid Based Med.

18.Smith JD, MacDougall CC, Johnstone J, Copes RA, Schwartz B, Garber GE. 2016. Effectiveness of N95 respirators versus surgical masks in protecting health care workers from acute respiratory infection: a systematic review and meta-analysis. CMAJ. 188(8): 567-574

19.Radonovich J, Simberkoff MS, Bessesen MT, Brown AC. 2019. N95 Respirators vs Medical Masks for Preventing Influenza Among Health Care Personnel: A Randomized Clinical Trial. JAMA. 322(9):824-833

20.Seto WH, Tsang D, Yung RW. 2003. Effectiveness of precautions against droplets and contact in prevention of nosocomial transmission of severe acute respiratory syndrome (SARS). Lancet. 361(9368):1519-1520

21. Teleman MD, Boudville IC, Heng BH, Zhu D, Leo YS. 2004. Factors associated with transmission of severe acute respiratory syndrome among health-care workers in Singapore. Epidemiol Infect. 132(5):797-803

22. Wen Z, Yu L, Yang W. 2013. Assessment the protection performance of different level personal respiratory protection masks against viral aerosol. Aerobiologia (Bologna). 29(3):365-372

23.Lee SA, Grinshpun SA, Reponen TA. 2008. Respiratory performance offered by $\mathrm{N} 95$ respirators and surgical masks: human subject evaluation with $\mathrm{NaCl}$ aerosol representing bacterial and viral particle size range. Occup Hyg. 52(3):177-85.

24. Liverman CT, Harris TA, Rogers MEB, Shine KI. 2009. Respiratory protection for healthcare workers in the workplace against novel H1N1 influenza A: A letter report. IOM (Institute of Medicine). Washington, DC: The National Academies Press.

25.Rebmann T, Carrico R, Wang J. 2013. Physiologic and other effects and compliance with long-term respirator use among medical intensive care unit nurses. Am J Infect Control, 41:1218-1223

26. Van Doremalen N, Bushmaker T, Morris DH. 2020. Aerosol and surface stability of SARS-CoV-2 as compared with SARS-CoV-1 N Engl J Med. 382:1564-1567

27. Yamada $\mathrm{H}$, Ishihama K, Yasuda K, Hasumi-Nakayama Y, Shimoji Y, Furusawa K. 2011Aerial dispersal of blood-contaminated aerosols during dental procedures. Quintessence International 42:5 
28. Rautemaa R, Nordberg A, Wuolijoki-Saaristo K, Meurman JH. 2006. Bacterial aerosols in dental practice - a potential hospital infection problem? Journal of Hospital Infection. 64:76-81.

29. Ravenel TD, Kessler R, Teich ST, Comisi JC, Kelly A, Renne WG. 2020. Evaluation of the Spatter-Reduction Effectiveness and Aerosol Containment of 8 Dry-Field Isolation Techniques. Quintessence

30.HSE. 2016. The effect of wearer stubble on the protection given by Filtering Facepieces Class 3 (FFP3) and Half Masks. Health and Safety Laboratory.

31. HSE. 2008. Evaluating the protection afforded by surgical masks against influenza bioaerosols.

32. World Health Organisation. 2020. Requirements and technical specifications of personal protective equipment (PPE) for the novel coronavirus (2019-ncov) in healthcare settings. [Accessed 2020 May 16] https://www.who.int/emergencies/ diseases/novel-coronavirus-2019/related-health-issues

33. World Health Organisation. 2020. Rational use of personal protective equipment (PPE) for coronavirus disease (COVID-19) [accessed 2020 May 16] https://apps.who.int/iris/bitstream/handle/10665/331498/WHO-2019-nCoVIPCPPE_use-2020.2-eng.pdf

Figures and Images

Figure 1. Respiratory droplets released through talking, coughing, or sneezing CDC Public Health Image library ID 11162. [accessed 2020 May 16] http://phil.cdc.gov/phil/details.asp?pid=11162

Figure 2. An example of an N95 respirator.

US Occupational Safety \& Health Administration. Презентация OSHA OSHA's Respiratory Protection Standard 29 CFR 1910.134 [accessed 2020 May 16] https:// www.osha.gov/dte/library/respirators/presentation/index.html

Figure 3. An infographic on respirator usage.

National Institute for Occupational Safety and Health. 2016. Respiratory Protection Infographics. [accessed 2020 May 16] https://www.cdc.gov/niosh/npptl/n95dayinfographics.html

Figure 4. An example of skin fomites from the wearing of respirators for long periods Amanda Ramalhoo. 2020. Instagram [accessed 2020 May 16] http://www.instagram.com/amanda.ramalhoo

Figure 5. A Fit testing procedure being carried out to check respirator seal. U.S. Navy photo by Photographer's Mate 3rd Class Jason T. Poplin. United States Navy. ID 031202-N-5821P-001 [accessed 2020 May 16] http://www.navy.mil/ view_image.asp?id=10859 